\title{
TECNOLOGIA ASSISTIVA NO ÂMBITO EDUCACIONAL PARA O ALUNO SURDO
}

\section{ARTIGO ORIGINAL}

LIMA, Eliane Maria dos Santos ${ }^{1}$

LIMA, Eliane Maria dos Santos. Tecnologia assistiva no âmbito educacional para o aluno surdo. Revista Científica Multidisciplinar Núcleo do Conhecimento. Ano 05, Ed. 06, Vol. 06, pp. 66-74. Junho de 2020. ISSN: 2448-0959, Link de acesso: https://www.nucleodoconhecimento.com.br/educacao/aluno-surdo

\section{RESUMO}

O presente trabalho foi desenvolvido a partir de uma pesquisa baseada em autores que discutem sobre a Tecnologia Assistiva na Educação de Surdos, este objetiva investigar as contribuições destas tecnologias no processo de ensino aprendizagem das pessoas com deficiência auditiva e surdas dentro das escolas. E de maneira específica almeja analisar as suas relevâncias na construção da aprendizagem dos alunos surdos, verificando a utilização dessa ferramenta como mediação na inclusão das pessoas com surdez ou deficiência auditiva. A partir dos dados obtidos, detectamos que as escolas que trabalham com as Tecnologias Assistivas, os alunos com deficiência têm uma maior independência, qualidade de vida e inclusão social, através da ampliação de sua comunicação, habilidades de seu aprendizado e trabalho. As novas tecnologias têm sido fundamentais para esse caminho de descobertas, inclusão e também da superação dos obstáculos, para gradativamente integram e socializam o aluno bem como a equipe da escola a ele.

Palavras-chave: Inclusão, surdo, Tecnologia Assistiva.

${ }^{1}$ Pós graduação em Língua Brasileira de Sinais, graduação em Pedagogia e Letras. 


\section{INTRODUÇÃO}

As tecnologias estão inseridas nos mais diversos contextos cotidianos da humanidade, como meio contínuo de solucionar as suas necessidades e assim, sanar problemas, remover barreiras e simplificar ações e atividades. Sendo assim, o presente trabalho considera a importância do uso destas Tecnologia Assistiva no âmbito educacional para aluno surdo ou com deficiência auditiva que, anteriormente apresentavam acesso restrito ao conhecimento, por não terem ingresso a estes meios.

De acordo com o Portal Educação (2019), ao longo da história da Educação de Surdos, estes sofreram preconceitos dos mais diversos, sendo que, chegando até a serem excluídos do convívio social e proibidos de exercerem direitos como: receber heranças e matrimônio. Dessa forma, nossa pesquisa contribui para visualizar alguns tópicos, e analisar o processo de inclusão de alunos com surdez e deficiência auditiva em sala de aula regular.

É de suma importância frisar que, as Tecnologia Assistivas, quando bem usufruídas pelo os professores podem apoiar mutuamente o processo de ensino aprendizagem dos alunos surdos ou com deficiência auditiva, ressignificando assim o processo de inclusão através de ferramentas e recursos tecnológicos que valorizem a sua identidade enquanto sujeitos surdos dotados de uma cultura própria.

Sendo assim, o nosso intuito é frisar, o professor que trabalha junto com as tecnologias assistivas tem a função de mediador do conhecimento tornando possível aos alunos com deficiência auditiva e surdez a comunicação com o mundo que os cercam, colaborando para suprir todas as suas dificuldades, e assim contribuir de forma significativa para com o seu crescimento intelectual, dando-lhes, assim a oportunidade de expressar seus sentimentos por meio do contato com os mais diversos gêneros textuais. 


\section{METODOLOGIA}

O presente trabalho foi desenvolvido através de uma pesquisa bibliográfica de cunho qualitativo com base nos autores Morais, Morais e Oliveira, a partir desta metodologia é possível analisar o uso das Tecnologias Assistiva na educação dos surdos, as quais efetivam-se de forma a garantir ao aluno condições necessárias para a sua plena participação na sociedade, garantindo assim igualdade com os demais membros da comunidade em que vivem, com a promoção de oportunidades de desenvolvimento pessoal, educacional, social e profissional. A pesquisa bibliográfica, de acordo com Gil (2008, p. 50) "é desenvolvida a partir de material já elaborado, constituído principalmente de livros e artigos científicos" e tem como principal benefício expandir o campo de pesquisa do investigador, o que não seria possível em uma pesquisa direta. Dentro dessa proposta, recorremos a pesquisas em revistas científicas que abordam o tema estudado, enriquecendo assim os dados para análise da situação problema, utilizando como base estudos publicados em artigos dos autores já citados acima.

\section{REFERENCIAL TEÓRICO}

O aparato teórico desta pesquisa, inicia-se com uma breve trajetória sobre o processo histórico da educação de surdos. Diversas são as fontes que remente-nos a este panorama e muitas levam-nos a informações imprecisas, sobre a surdos na antiguidade. Diante deste contexto, muitas são as indagações de como ocorreu este processo, mas com convicção só temos a de que de acordo com a história da Educação de Surdos no mundo os mesmos eram totalmente marginalizados. Ao longo da História, continuaram a sofrer preconceitos de toda espécie, sendo, comumente excluídos do convívio social e proibidos de exercerem direitos como: o recebimento de heranças e o casamento (PORTAL EDUCAÇÃO, 2019).

A fim de refletir sobre esta hostil trajetória educacional e também compreendermos algumas divergências as quais atualmente penetram na Educação de Surdos, ressaltamos que, durante longos anos os surdos foram considerados como seres incapazes de exercerem qualquer tipo de atividade na sociedade, como por exemplo 
na Grécia antiga onde os estes eram tidos como insensíveis e irracionais. Época que, eram tratados como seres incompetentes e que, por não possuírem uma linguagem não eram capazes de raciocinar. Assim, não tinham direitos, eram marginalizados e muitas vezes condenados à morte (PORTAL EDUCAÇÃO, 2012).

Adentrarmos nesta história e assim, assimilamos informações que nos remete ao contexto de marginalização não só do indivíduo surdo, mas, das pessoas com deficiência de um modo geral mas, destacamos em especial neste trabalho os "surdos-mudos", denominação da época. Estes indivíduos eram tratados de formas diferentes em algumas regiões ao redor do mundo uns, os tratavam como castigos dos Deuses, outros como seres sobrenaturais e até como seres abençoados. Muitas foram as atrocidades acometidas para com os surdos nesta longa jornada, muitos eram abandonados à própria sorte, outros sacrificados, indomesticáveis, tratados com gestos de caridade, piedade, rejeição. Foi assim que deu-se o surgimento da história da Educação de Surdos no Mundo, a qual conhecemos atualmente.

Diante deste contexto, objetivamos pesquisar quais as tecnologias assistivas (TA) puderam atribuir ao indivíduo surdo, meios favoráveis ao seu processo de desenvolvimento em uma sociedade ouvinte, meios que, foram fortes aliados aos profissionais da educação dentro no espaço escolar. De acordo com pesquisas podemos averiguar meios tecnológicos que favoreçam mutuamente este grupo tanto dentro como fora da Escola.

Assim, iniciamos refletindo sobre o uso destas tecnologias na vida pessoal do indivíduo surdo, pois graças a estás foram identificados os graus de surdez, e assim o som pode ser categorizado por meio de frequência, amplitude e timbre, mediando a audição entre as frequências de 250 a $8.00 \mathrm{Hertz}(\mathrm{Hz})$ e os seus limites de amplitude de 0 a 110 decibéis $(\mathrm{dB})$, sendo assim, o som passou a ser avaliado por meio das frequências de 500, 1.000 e $2.000 \mathrm{~Hz}$, avaliado por meio de testes de audiometria (BRASIL, 2006)

Com tais informações acerca da perda auditiva, é notório que a tecnologia assistiva favoreceu o processo de educação dos surdos, pois a partir de então foram 
elaboradas tecnologias que viessem a sanar esta perca auditiva do individuo surdo. Sabemos que, o ser humano necessita da audição para a aquisição do som, mas, diante daqueles que, apresentam dificuldades na assimilação e compreensão destes, as tecnologias assistivas TA foram emergindo como meios facilitadores na vida educacional e social. Cientes da importância das TA no contexto geral da humanidade moderna estas atualmente tornam-se a base de tudo em nossas vidas, e a comunidade surda propôs avanços que, garantiu-lhes de forma efetiva a sua plena participação na sociedade ouvinte.

As possibilidades de usufruir das novas tecnologias não se aplicam tão somente a educação, mas ao universo de convivência com o ambiente externo, os equipamentos favorecem a adaptação do corpo para a comunicação com o mundo externo, e no ponto de vista dos surdos o uso do computador e da Internet construiu uma ponte com novas possibilidades de comunicação, sendo entregue como um presente (OLIVEIRA, 2010).

Sendo assim, o processo de ensino aprendizagem ao longo do tempo, vem dispondo por meio das Tecnologias Assistivas, aos profissionais da educação métodos eficazes que favorecem a aprendizagem do surdo, levando-os a desenvolverem suas práticas de leitura (sinalizada) e escrita (português). Portanto as TA emergem como meio potencializador da aprendizagem, como um processo educacional inovador que, oportunizam um mundo visual para os surdos, proporcionando-lhes inúmeras mudanças em seu processo de aquisição da Língua L1.

Dessa forma, resolvemos listar uma série de ferramentas tecnológicas que auxiliam o surdo em seu cotidiano de modo geral:

$\checkmark$ TDD (equipamento de telecomunicação para surdos trata-se de um aparelho que conectado ao telefone, transforma as frases ditas pelo o interlocutor em mensagens escritas):

$\checkmark$ Rybená Programa gratuito, instalado em telefone celulares: 
$\checkmark$ SMS:

$\checkmark$ Closed Caption ou legenda oculta é um sistema de transmissão de legendas podem ser reproduzidos para uma TV que possua função para tal:

$\checkmark$ Videoconferência:

$\checkmark$ ProDeaf :

$\checkmark$ Livros digitais:

$\checkmark$ Tblets e Smartphones:

$\checkmark$ Hand Talk aplicativo de celular:

Diante do que foi exposto, podemos perceber a infinidade de meios tecnológicos que emergiram de modo geral com o advento das TA mas que, favoreceram mutuamente as dificuldades auditivas do indivíduo surdo na sociedade, principalmente na escola, pois estes garanti-Ihes uma aprendizagem significativa. Assim, fica evidente que a tecnologia assistiva no âmbito educacional para o aluno surdo é um instrumento poderosíssimo, pois dispõe de meios que favorecem não só o processo de aprendizagem do surdo mais também a sua comunicação.

As tecnologias emergiram e, passaram a garantir grandes possibilidades de acesso ao conhecimento como um todo, e nesta perspectiva foi possível descrevermos aspectos relevantes para o apoio a Educação de Surdos.

\section{RESULTADOS E DISCUSSÃO}

A utilização das Tecnologia Assistiva no âmbito escolar, a partir das análises dos autores estudados, contribuíram significativamente para o processo de ensino aprendizagem do indivíduo surdo, dando-Ihes autonomia, e garantido-Ihes de fato uma inclusão significativa. 
De acordo com esta visão Koch (2013, p.11) nos traz este conceito.

Nesta perspectiva, as novas tecnologias de comunicação passam a desempenhar um papel vital neste processo. Assim, considera-se um desafio problematizar e investigar as práticas educacionais afim de enriquecê-las e propor assim sempre que possível novo saber para os professores, que estarão investigando e refletindo sua ação docente, buscando novas estrategias de ensino, para que o educando se aproprie de maneira significativa do conhecimento elaborado através das tecnologias do cotidiano escolar.

Sendo assim, a escola deve estar atenta a estas tecnologias para então facilitar e garantir esta aquisição de conhecimento, que poderá ser melhor explorada quando os profissionais da educação tiverem embasamentos acerca da classificação de perda auditiva, facilitando assim, a aquisição de meios que favorecerão a assimilação contínua da aprendizagem.

No quadro a seguir a seguir poderemos além de classificar o tipo de surdez a qual varia da leve a profunda, como também categorizar o som e assim as TA poderão não só auxiliar os profissionais da Educação de uma forma mais especifica de acordo com cada classificação, como poderão emergirem novas tecnologias para sanar dificuldades advindas a cada grupo:

Quadro 1 ( Classificação, graus de perda e características de perda auditiva)

\begin{tabular}{|c|c|c|}
\hline Classificação & perda & Características \\
\hline Leve & 20 a $40 \mathrm{~dB}$ & $\begin{array}{l}\text { Indivíduos que apresentam certas limitações em } \\
\text { assimilarem todos os sons, mas, assimilam a língua } \\
\text { naturalmente, quando está na fase de assimilação da } \\
\text { língua pode trocar alguns sons e letras que apresentam } \\
\text { similaridades. }\end{array}$ \\
\hline
\end{tabular}




\begin{tabular}{|l|l|l|}
\hline Moderada & 20 a $70 \mathrm{~dB}$ & $\begin{array}{l}\text { Indivíduos que apresentam dificuldades em } \\
\text { compreender frases mais complexas, necessitando de } \\
\text { altivez na voz para poderem compreender bem. }\end{array}$ \\
\hline Severa & $\begin{array}{l}70 \text { a } 90 \mathrm{~dB} \\
\text { O indivíduo para ser ouvido precisa de uma voz forte, e } \\
\text { a compreensão da língua necessitara de recursos } \\
\text { visuais }\end{array}$ \\
\hline Profunda & $\begin{array}{l}\text { Superior } \\
90 \mathrm{~dB}\end{array}$ & $\begin{array}{l}\text { O indivíduo não apresenta a aquisição da linguagem } \\
\text { oral por este motivo não assimilam e nem desenvolvem } \\
\text { a comunicação oral. }\end{array}$ \\
\hline
\end{tabular}

Fonte: (Davis e Silverman, 1978).

Outro fator relevante é a disponibilidade de adaptação de recursos didáticos tecnológicos e de acessibilidades para possibilitar a realização e a participação dos alunos com e sem deficiências nas atividades desenvolvida no ambiente escolar. À exemplo da percepção visual que é de suma importância para o processo de ensino aprendizagem do indivíduo surdo, como o uso de data show para apresentação de slides com imagens relacionados ao conteúdo trabalhado pelo professor e sendo assim, facilitando o entendimento e aquisição dos conhecimentos programáticos.

Diante deste contexto ficou claro que, quando se coloca em prática o uso dos aparelhos de Tecnologia Assistiva na escola, estes contribuem significativamente para a melhoraria da aprendizagem dos alunos surdos ou com deficiência auditiva, além de proporcionar aulas lúdicas e dinâmicas. Assim a escola garanti acessibilidade comunicacional a todos os seus alunos, e o professor assume a figura de mediador pois, o uso dos equipamentos tecnológicos neste espaço escolar reconduzem ao desenvolvimento cognitivo, intelectual e cultural dos seus membros.

Outro fator relevante que, pode favorecer o processo de aquisição do indivíduo surdo é, termos conhecimentos acerca dos graus de perda auditiva, por meio da categorização do som este que, é avaliado por meio de sua frequência, amplitude e timbre, sendo avaliado por meio de testes audiométricos que variam entre as 
frequências de 250 a $8.00 \mathrm{Hertz}(\mathrm{Hz})$ e os seus limites de amplitude de 0 a 110 decibéis $(\mathrm{dB})$.

Quadro 2: Graus de Perdas Auditivas (BRASIL, 2006)

\begin{tabular}{|l|l|}
\hline Classificação & Decibéis \\
\hline Limites normais & 0 a 25 \\
\hline Perda leve & 26 a 40 \\
\hline Perda Moderada & 41 a 70 \\
\hline Perda Severa & 71 a 90 \\
\hline Perda Profunda & Acima de 90 \\
\hline
\end{tabular}

Fonte: (Davis e Silverman, 1978).

Dessa forma, há inúmeros elementos que estão ao nossos inteiro dispor tanto dentro como fora da escola que, facilitarão as práticas pedagógicas para o processo de ensino aprendizagem do indivíduo surdo, partindo das TA mais simples as mais complexas como por exemplo a Escrita da Língua de sinais, que poderá ser um tema abordada em outros trabalhos mas, que todas emergem com o intuito de promover acessibilidade e inclusão dos surdos ao mundo da Literatura.

\section{CONSIDERAÇÕES FINAIS}

Dessa forma inferimos que, o processo de desenvolvimento dos seres humanos surgi da interação de cada um com o meio em que vive, e o uso das Tecnologias Assistivas no âmbito educacional veio como um recurso tecnológico que possibilita este desenvolvimento, otimizando as potencialidades de cada aluno.

A partir dos resultados encontrados entendemos que, o uso dessa metodologia por esses aparelhos, emergiram como meio facilitador e efetivo a comunidade surda, pois contribui não só para o processo de ensino aprendizagem dos alunos com necessidades educativas específicas mas, também ao aluno surdo. 
Assim ressaltamos que, este processo de aprendizagem não pode ser definido como restrito, pois este compõe um currículo inclusivo e não poderá ser tratado de forma dissociada em sala de aula. A escola precisa está preparada para receber o aluno independente de suas condições, mesmo havendo insuficiência na disponibilidade de recursos para atender as suas especificidades é, necessário que os docentes e a comunidade escolar busquem conhecimentos sobre a amplitude e a importância do uso da Tecnologia Assistiva para os indivíduos surdos. Uma vez que, o uso destes aparelhos possibilitam a superação das limitações e de barreiras comunicacionais encontradas nas, atividades cotidianas do espaço escolar.

Os estudos realizados para a efetivação deste trabalho, leva-nos a perceber os avanços tecnológicos no sistema público regular de ensino, possibilitando e efetivando o acesso da comunidade surda a este espaço, este que a cada dia mais prepara-se para torna-se um ambiente que acolhe a todos, efetivando uma sociedade justa e igualitária que garante de fato uma Educação para todos.

\section{REFERÊNCIAS}

BRASIL. Ministério da Educação. Secretaria de Educação Especial. Saberes e práticas da inclusão desenvolvendo competências para 0 atendimento às necessidades educacionais especiais de alunos surdos. Brasília. 2006. Disponível em: http://portal.mec.gov.br/seesp/arquivos/pdf/alunossurdos.pdf. Acesso em jan.2020

CRUZ, Evandro Costa; COSTA, Deuzeli Brandão da. A Importância da Formação Continuada e sua Relação com a Prática Docente. Revista Científica Multidisciplinar Núcleo do Conhecimento. Edição 08. Ano 02, Vol. 03. Pág. 42-58, novembro de 2017. ISSN:2448-0959.

Disponível em https://www.nucleodoconhecimento.com.br/educacao/formacao-continuada. Acesso em fev.2020

$\mathrm{KOCH}$, Z.M. As tecnologias no cotidiano escolar: Uma Ferramenta Facilitadora do Processo de Ensino-Aprendizagem. RS. Brasil 2013 Disponível em: 
https://repositorio.ufsm.br/bitstream/handle/1/498/Koch_Marlene_Zimmermann.pdf?s equence=1. Acesso em: 10 jan.2020

OLIVEIRA, Nazarerth Ana Lirio de. As Tecnologias e a Educação de Alunos Surdos. Monografias Brasil Escola. $2010 . \quad$ Disponível em: https://monografias.brasilescola.uol.com.br/pedagogia/as-tecnologias-educacaoalunos-surdos.htm. Acesso em fev.2020

PORTAL EDUCAÇÃO.A história dos surdos. 2012. Disponível em: https://siteantigo.portaleducacao.com.br/conteudo/artigos/educacao/historia-daeducacao-de-surdos/65157. Acesso em jan.2020

SOUZA, Rosemeri Bernieri. Língua brasileira de sinais - libras II./ Rosemeri Bernieri de Souza - Indaia: UNIASSELVE, 2018.

Enviado: Fevereiro, 2020.

Aprovado: Junho, 2020. 